\title{
Waste Composite Sensor Designed by Cellulose and Activated Carbon as Ethylene Absorber
}

\author{
S. Ummartyotin ${ }^{1,2}$ and C. Pechyen ${ }^{1,2}$ \\ ${ }^{1}$ Advanced Functional Polymeric Materials Research Group, Faculty of Science and Technology, \\ Thammasat University, Patumtani 12120, Thailand \\ ${ }^{2}$ Materials Research Center, HORIBA Scientific and Thammasat University, Patumtani 12120, Thailand
}

Correspondence should be addressed to S. Ummartyotin; sarute.ummartyotin@gmail.com

and C. Pechyen; chiravoot.p@gmail.com

Received 3 April 2016; Accepted 11 May 2016

Academic Editor: Ming-Guo Ma

Copyright ( 2016 S. Ummartyotin and C. Pechyen. This is an open access article distributed under the Creative Commons Attribution License, which permits unrestricted use, distribution, and reproduction in any medium, provided the original work is properly cited.

\begin{abstract}
Activated carbon was successfully derived from scrap tile waste from thermochemical conversion. Chemical and physical modifications were therefore employed to modify the specific surface area and porosity of activated carbon. Cellulose was successfully extracted from palm front. Designation of waste composite was prepared by cellulose and activated carbon. Less than $30 \mathrm{wt} \%$ of activated carbon was integrated into cellulose sheet matrix. It was important to note that there is no change in mechanical and morphological properties. Small amount of activated carbon was well dispersed. In order to investigate the feasibility of composite as active packaging, oxygen permeation rate and ethylene gas adsorption ability were preliminary investigated.
\end{abstract}

\section{Introduction}

In recent years, the push towards the development of biobased materials has been evident. Numerous approaches have been extremely investigated on the feasibility of biobased materials for many purposes. The emergence of biobased material played an important role on many industrial sectors such as automotive part, electronic device, pharmaceutical and medical research, and food technology [17]. Up to the present time, the category of biobased material was versatile depending on available resources. It was related to cellulose and its derivative, chitin-chitosan, polylactic acid, polybutylene succinate, and starch. The use of biobased materials was therefore selected due to environmentally friendly purpose, nontoxicity, and value-added concept for agricultural product. On the other hand, biobased materials were therefore considered as biomass. The existence of these biobased resources should be preferably investigated as well as their feasibility in order to replace the conventional nonrenewable materials. Moreover, due to the growth of worldwide population, it should be encouraged that the emergence of novel technology based on "green product and process" be endorsed. It was involved in the design of product and process which minimizes the use and the generation of hazardous materials. To become innovative in green technology, numerous approaches have been investigated from academic research to industrial commercialization. One of the excellent strategic routes was related to waste development.

To the best of our knowledge, the management of municipal solid waste was considered as important issue for city authorities and planners due to increment in population, urbanization, and limited land space. It was consequently considered as the major concern to environmental health [8-13]. This probably had many effects on environmental treatment challenges such as leachate generation and air pollution. As a consequence, it may combine with political, social, and economic issues, as well as the availability of land, which were major concerns to be addressed in land evaluation and management. In addition, increment in worldwide population led to increase in fossil fuel consumption, rendering increment in greenhouse gas emission. This might be considered as environmental issue. In order to solve 
this technical issue, converting solid waste to conventional product was favorably remarked to be an option. To be sustainable and renewable, the design of product based on solid waste should be preferably developed. This concept led to solving the landfill space, environmental issue as well as nonpollution.

To respond to this scenario, waster composite was considered as an important key challenge to solve this issue [1416]. One solid waste was due to activated carbon derived from scrap tile waste. From the fundamental point of view, scrap tire throughout the world is approximately 1 billion per year and it sets to be increased in the future as car and truck transportation continues to expand. Up to the present time, reutilization of scrap tile was comparatively much below annually generated tire. One of the successful strategic approaches of the reutilization of scrap tile waste was involved in activated carbon formation. After pyrolysis of scrap tile waste, the existence of activated carbon with high specific surface area and porosity was presented. It was considered as a viable market for the end product of the waste [17-20]. On the other hand, another waste was involved in cellulose derived from palm frond. At this presence, palm frond was relatively considered as biomass. The availability of palm frond was therefore versatile in many areas of academic research and industrial commercialization [21-23]. To the best of our knowledge, utilization of palm frond was related to biorefinery which comparatively referred to a promising concept of utilizing biomass or any other renewable resources as feedstock to produce energy and platform chemicals and materials $[24,25]$. It was definitely considered as one of the excellent techniques to reduce carbon footprint and dependency on fossil fuel for sustainable development. One of the excellent strategic approaches of biorefinery of palm frond was biological production of cellulose. From conventional reaction, cellulose was therefore derived from palm frond. The properties of cellulose were evident to have numerous features such as high thermal stability, chemical resistance, and excellent mechanical properties.

In order to have a successful waste development program, the design on composite from waste was therefore investigated. Activated carbon was successfully derived from scarp tile waster, whereas cellulose was extracted from palm frond. The structure and properties of waste based composite were therefore evaluated based on ethylene absorber.

\section{Experimental}

2.1. Chemical Reagents and Materials. Scrap tile was provided as a gift from Patomchai Hitech Co., Ltd., Nakhon Pathom, Thailand. Analytical grade of hydrochloric acid, $\mathrm{HCl}$, was purchased from Merck (analytical reagent assay 37\%, Merck KGaA, Darmstadt, Germany). Analytical grade of sulfuric acid, $\mathrm{H}_{2} \mathrm{SO}_{4}$, was also purchased from Merck (analytical reagent assay 95\%, Merck KGaA, Darmstadt, Germany). Analytical grade of sodium hydroxide $(\mathrm{NaOH})$ was purchased from Sigma Aldrich, Thailand. All chemical reagents were used as received without further purification. Palm frond was provided as a gift from Oil Palm Estate, Thailand.
2.2. Methods. Scrap tile as received was cut into small pieces. It was washed with deionized water and dried in an oven at $100^{\circ} \mathrm{C}$ for 24 hours. Afterwards, it had undergone pyrolysis process at $800^{\circ} \mathrm{C}$ for 1 hour. The dried scrap tile was ground and sieved into particle size smaller than $500 \mu \mathrm{m}$. The ratio of 1:1 of analytical grade of hydrochloric acid and sulfuric acid was poured into activated carbon. The reaction was set at $80^{\circ} \mathrm{C}$ for 2 hours. Then, it was filtered with Buchner funnel connected to a Buchner flask and a vacuum pump. It was washed with distilled water until neutral $\mathrm{pH}$. The obtained carbons were characterized by nitrogen adsorptiondesorption isotherms at $-196^{\circ} \mathrm{C}$. The surface area and total pore volume of activated carbons, which were determined by application of the Brunauer-Emmett-Teller (BET) and t-plot methods, were achieved as high as $604.31 \mathrm{~m}^{2} / \mathrm{g}$ and $0.715 \mathrm{~cm}^{3} / \mathrm{g}$, respectively. Prior to composite preparation, it was stored in desiccator in order to prevent moisture absorption. Freshly cut palm fronds were obtained from the Oil Palm Estate, Surat Thani, Thailand. The leaflet was left in the estate and only petiole part was taken for the characterization purpose. The palm frond was naturally sundried until the moisture content dropped to below $20 \%$. It was ground to a particle with diameter size of $2 \mathrm{~mm}$. The ground sample was sieved through $0.5 \mathrm{~mm}$ mesh to remove the powdery tiny particles (powder). The meshed sample was further dried at $45^{\circ} \mathrm{C}$ in an oven until the moisture content dropped below $10 \%$ before it could be used in water extraction. Cellulose derived from palm frond was related to paper-making process. It was chemically modified by using sodium hydroxide. The water was removed from the suspension through filtration with a Buchner funnel fitted with Polytetrafluoroethylene membrane filter $(0.1 \mathrm{~m}$ mesh, $90 \mathrm{~mm}$ diameter), which was connected to a Buchner flask and a vacuum pump. The volume of cellulose suspension was adjusted to achieve a bacterial cellulose disc with the dried weight of $0.25 \mathrm{~g}$. The filtration was continued until the wet sheet of cellulose was formed. The wet sheet was then dried between two Polytetrafluoroethylene membranes under the applied pressure of 58 psi. To fabricate waste composite small amount of activated carbon derived from scrap tile was integrated into cellulose sheet. The ratio of structure of composite was therefore evaluated. Properties of waste composite were investigated based on ethylene absorber.

\section{Results and Discussion}

Cellulose was successfully extracted from palm frond by conventional reaction technique. It was well dispersed in water. Additional information on cellulose properties was similar to our many previous literatures. As-extracted cellulose suspension was preliminary tested on active alkali. Lignin and its impurities were removed, and cellulose fibril was distributed into water based suspension form. On the other hand, activated carbon was successfully derived from scrap tile waste. The process was involved in pyrolysis under controlled atmosphere. Activated carbon was in the powderlike form in black color. It should be remarkably stored in desiccators in order to prevent water absorption issue. 


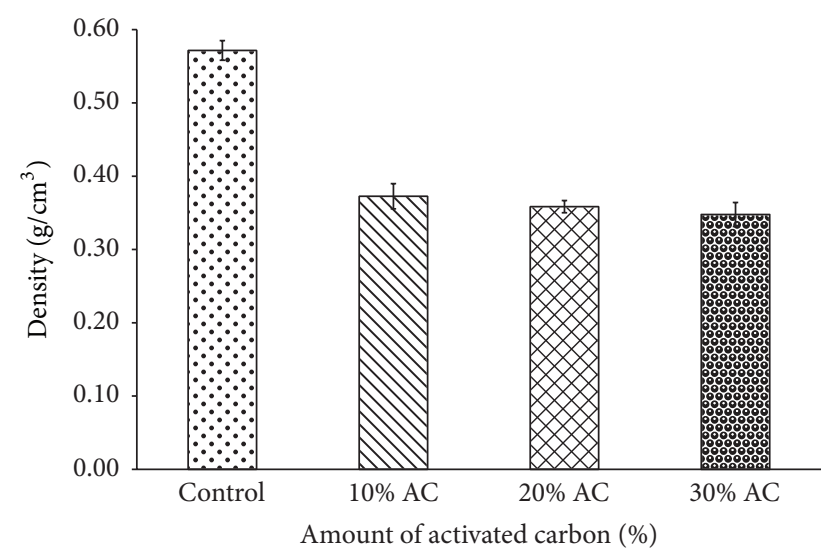

FIGURE 1: Density of activated carbon and cellulose sheet composite.

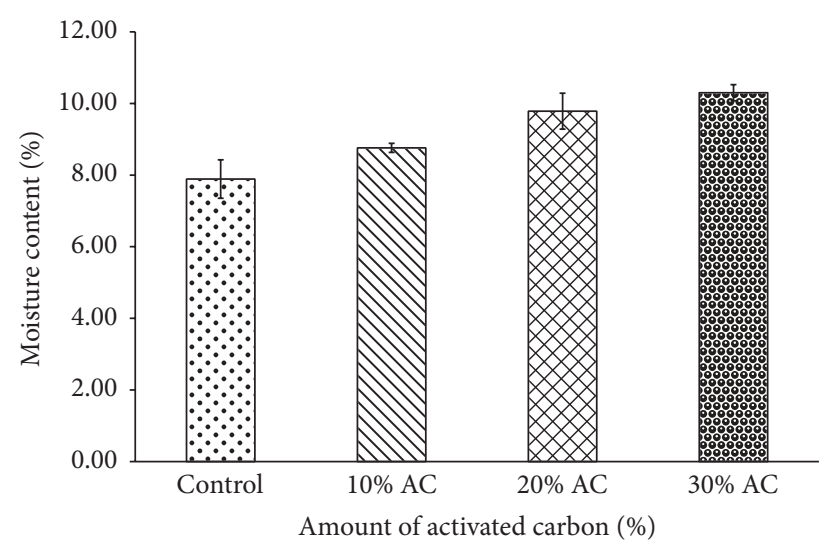

FIGURE 2: Moisture content of activated carbon and cellulose sheet composite.

To design cellulose and activated carbon based composite, less than $30 \mathrm{wt} \%$ of activated carbon was integrated into cellulose sheet. It was important to note that the density of composite was significantly less than neat cellulose sheet. Figure 1 exhibits the density of activated carbon and cellulose based composite. The neat cellulose sheet was provided for comparison. The existence of activated carbon can induce high porosity through the network. Due to its light weight, it can be therefore distributed into cellulose sheet. The activated carbon can therefore play an important role for the feasibility of its higher adsorption performance.

After that, moisture content and water absorption were therefore investigated for waste composite. Figures 2 and 3 exhibit the moisture content and water absorption of waste composite. The neat cellulose sheet was also provided for comparison. The ability of moisture content and water absorption ability of composite were significantly superior. From the structural point of view, the molecular structure of cellulose was composed of 3 positions of hydroxyl group; it was therefore easy to be activated for hydrogen bond formation in between cellulose molecular unit and water. Compared to waste composite, the existence of activated carbon was presented in cellulose network. It exhibited high specific surface area and porosity. Significant effort was made

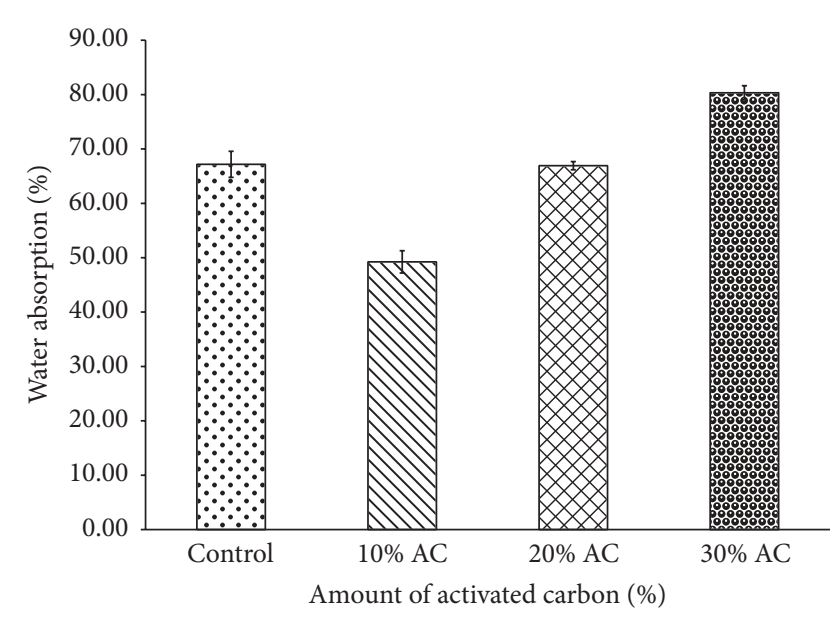

FIGURE 3: Water absorption of activated carbon and cellulose sheet composite.

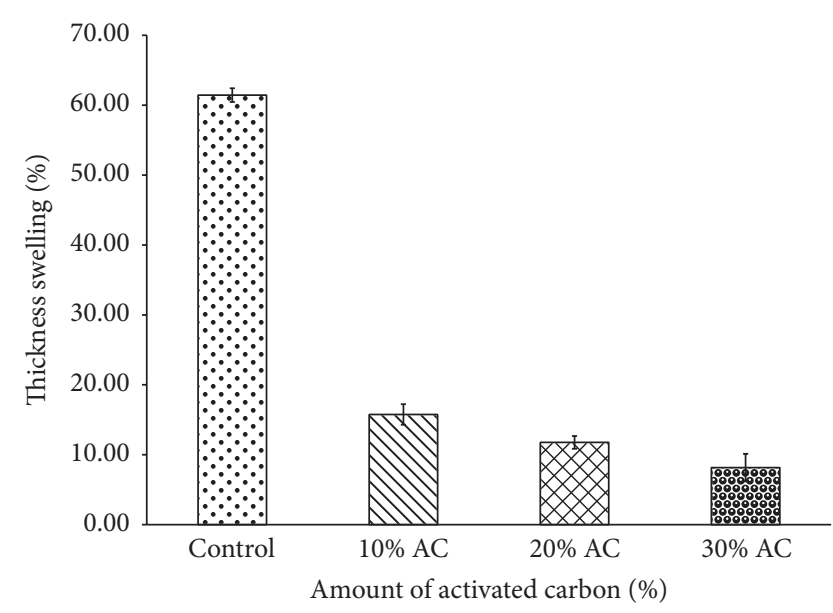

FIGURE 4: Thickness swelling of activated carbon and cellulose sheet composite.

to investigate waste composite for moisture content and water absorption ability. It was remarkable to note that, due to high absorption ability of cellulose and activated carbon, waste composite was successfully designed as absorbent material. However, it should be avoided due to the difference in physical properties. Cellulose was presented in sheet form, similar to paper, whereas activated carbon was successfully derived in powder form. The design of waste composite should be preferably considered regarding the mechanical properties if flexibility will be selected in particular application. On the other hand, the tendency of moisture content and water absorption was relatively high with the increment in percentage of activated carbon. It may be involved in agglomeration behavior of activated carbon and difficulty in controllable distribution of activated carbon. Although, the moisture content and water adsorption ability were still superior, the correlation of mechanical properties should be considered.

Thickness swelling was therefore evaluated and it is presented in Figure 4. It theoretically referred to mechanical strength of waste composite. The experiment was conducted 

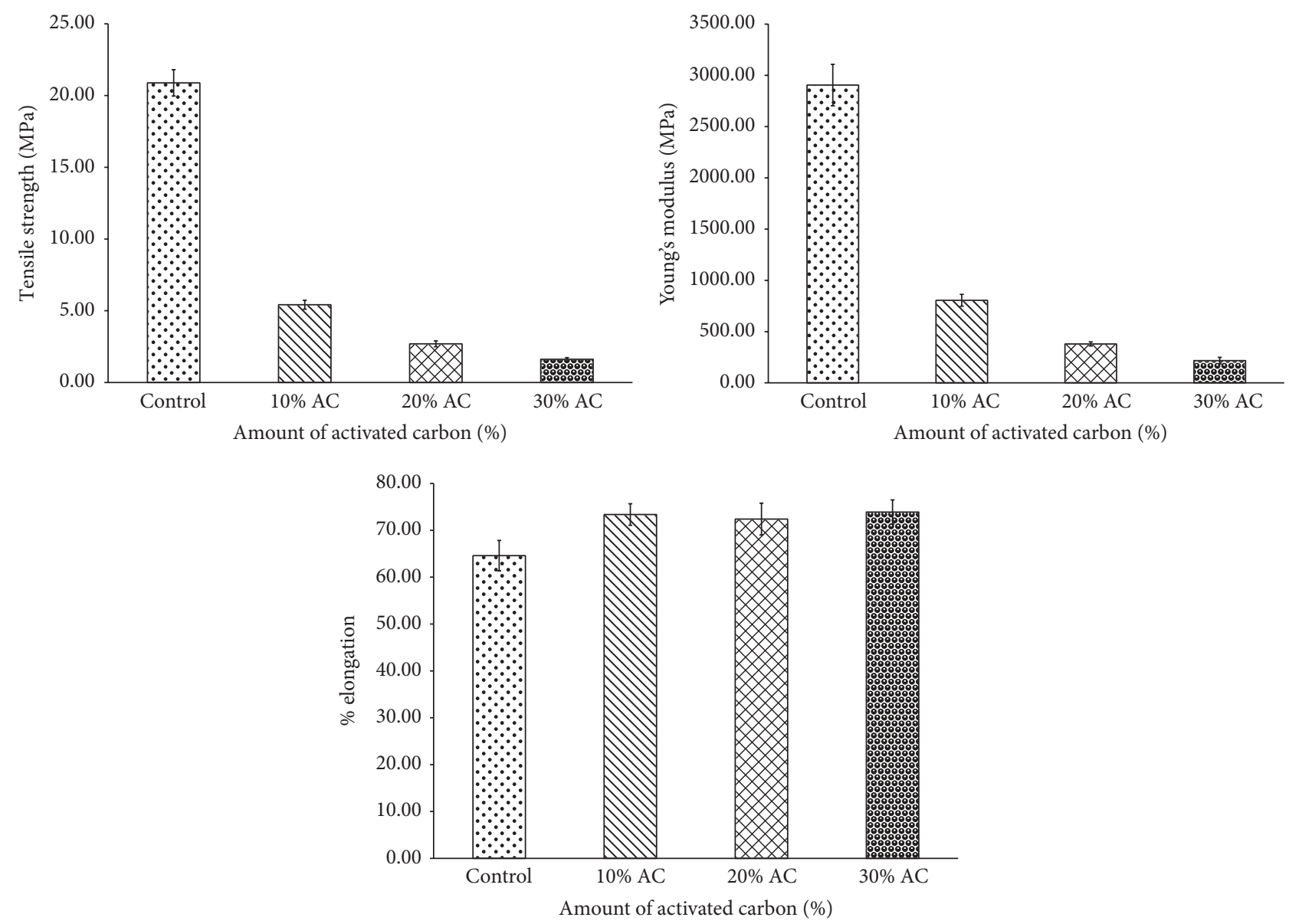

FIGURE 5: Mechanical properties of activated carbon and cellulose sheet composite.

at ambient temperature. The neat cellulose sheet was also provided for comparison. There is no effect of temperature on water absorption and mechanical properties in this part. It was important to note that significant reduction in thickness swelling was observed in waste composite. In case of cellulose sheet, there is free space between cellulose networks. Water molecule can be attached on the hydroxyl position of cellulose; it was therefore swelled. The thickness of sample was subsequently observed. On the contrary, this phenomenon was different compared to waste composite. The existence of activated carbon was considered as obstacle to swelling. Waste composite presented the good feature of dimensional stability. The percentage of thickness swelling was reduced from 60 to 15,12 , and $8 \%$, respectively.

Mechanical properties of activated carbon and cellulose sheet composite were therefore observed. The investigation was based on tensile strength, Young's modulus, and elongation at break, respectively. Figure 5 exhibits the mechanical properties of waste composite. The neat cellulose sheet was provided for comparison. It was remarkable to note that waste composite presented inferiority in technical data of tensile strength and Young's modulus. The activated carbon may agglomerate on the free space of cellulose fibril. The existence of activated carbon was provided for the difficulty of cellulose network on bonding formation. On the other hand, it was involved in sorption properties of activated carbon. Due to excellent specific surface area and porosity, it can be adsorbed both gas and liquid; significant reduction in tensile strength and Young's modulus was therefore investigated. On the other hand, the elongation at break of waste composite was still in similar region. The increment of elongation at break of waste composite was less than $5 \%$. The reason was due to the fact that the amount of activated carbon can be considered for two different purposes: adsorbed and controlled dimensional stability. It may be called the reinforcement part; no significance of elongation at break was therefore observed.

Morphological properties of activated carbon and cellulose sheet composite were therefore observed as exhibited in Figure 6. The neat cellulose sheet was provided for comparison. The morphology of cellulose sheet presented the fibril network. There is free space in between cellulose sheets. The orientation of cellulose sheet was random. The size of cellulose fibril was nonuniform. The aspect ratio (L:D) was estimated to be 15-20, depending on mechanical crushing technique. The variation in size of cellulose did not provide any significant alteration in adsorption ability. However, compared to waste composite, the small amount of activated carbon existed in the free space in between cellulose networks. With the higher amount of integration, it became 


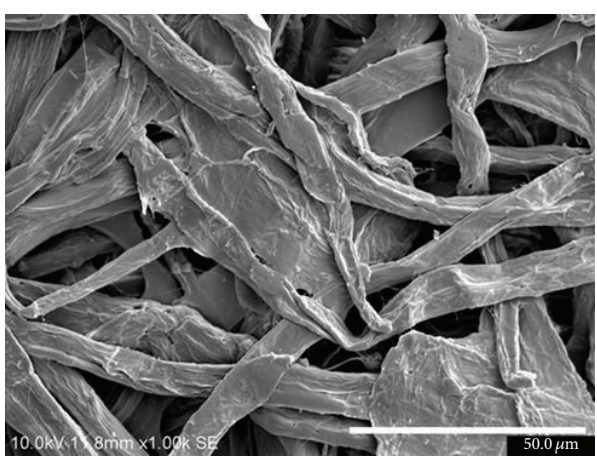

(a)

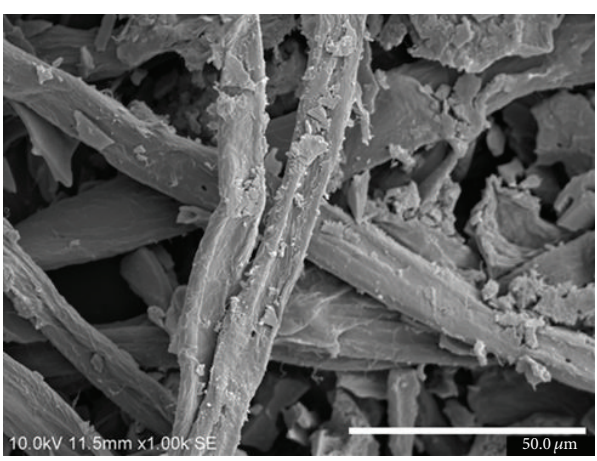

(c)

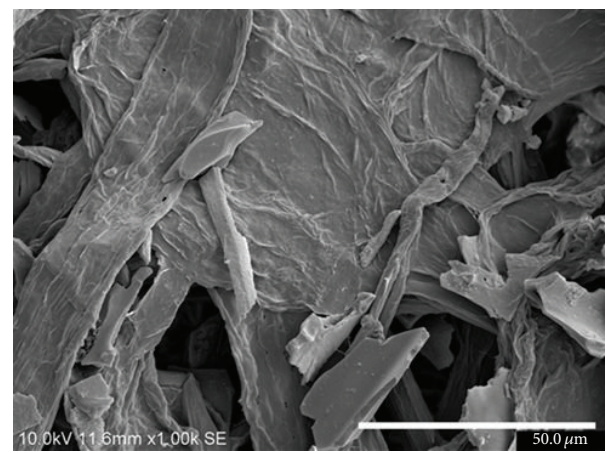

(b)

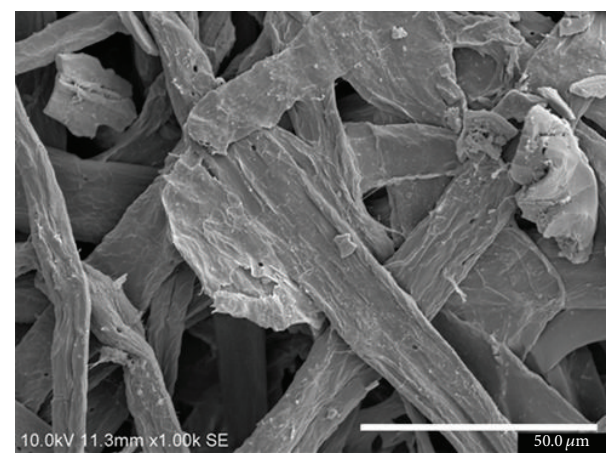

(d)

FIGURE 6: Morphological properties of activated carbon and cellulose sheet composite: (a) neat cellulose sheet, (b) $10 \mathrm{wt} \%$ of activated carbon filled cellulose sheet, (c) $20 \mathrm{wt} \%$ of activated carbon filled cellulose sheet, and (d) $30 \mathrm{wt} \%$ of activated carbon filled cellulose sheet.

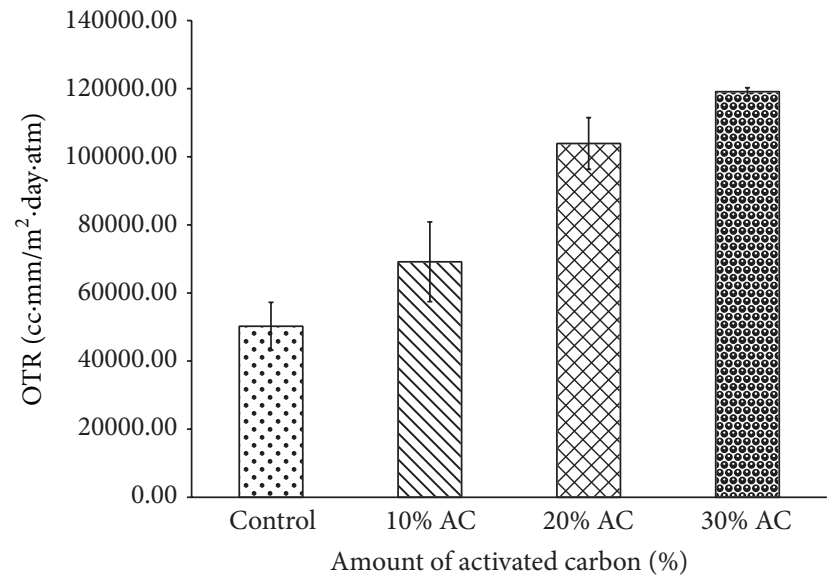

FIGURE 7: Oxygen transmission rate of activated carbon and cellulose sheet composite.

agglomerated. To avoid this agglomeration issue, correlation of amount of activated carbon and its processing should be controlled. However, the morphological properties of waste composite were not having any differences. It was presented in 3D network in cellulose sheet. Small amount of activated carbon existed in between.

Oxygen permeation test and ethylene gas absorption of activated carbon and cellulose sheet composite were investigated. Figures 7 and 8 exhibit the oxygen permeation

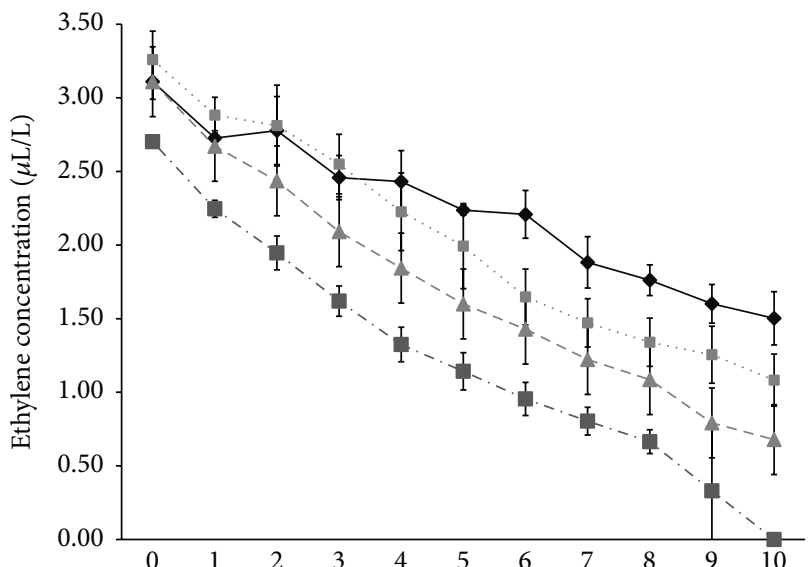

(h)

$$
\begin{array}{lr}
\rightarrow-\text { Control } & -20 \% \\
\rightarrow-10 \% & \cdots-30 \%
\end{array}
$$

FIGURE 8: Investigation of ethylene gas adsorption of activated carbon and cellulose sheet composite.

test and ethylene gas adsorption of waste composite. The neat cellulose sheet was provided for comparison. The ability of oxygen permeation of waste composite was superior compared to neat cellulose sheet. With the increment in activated carbon, significant enhancement in specific surface area and porosity was therefore observed. Oxygen gas was 


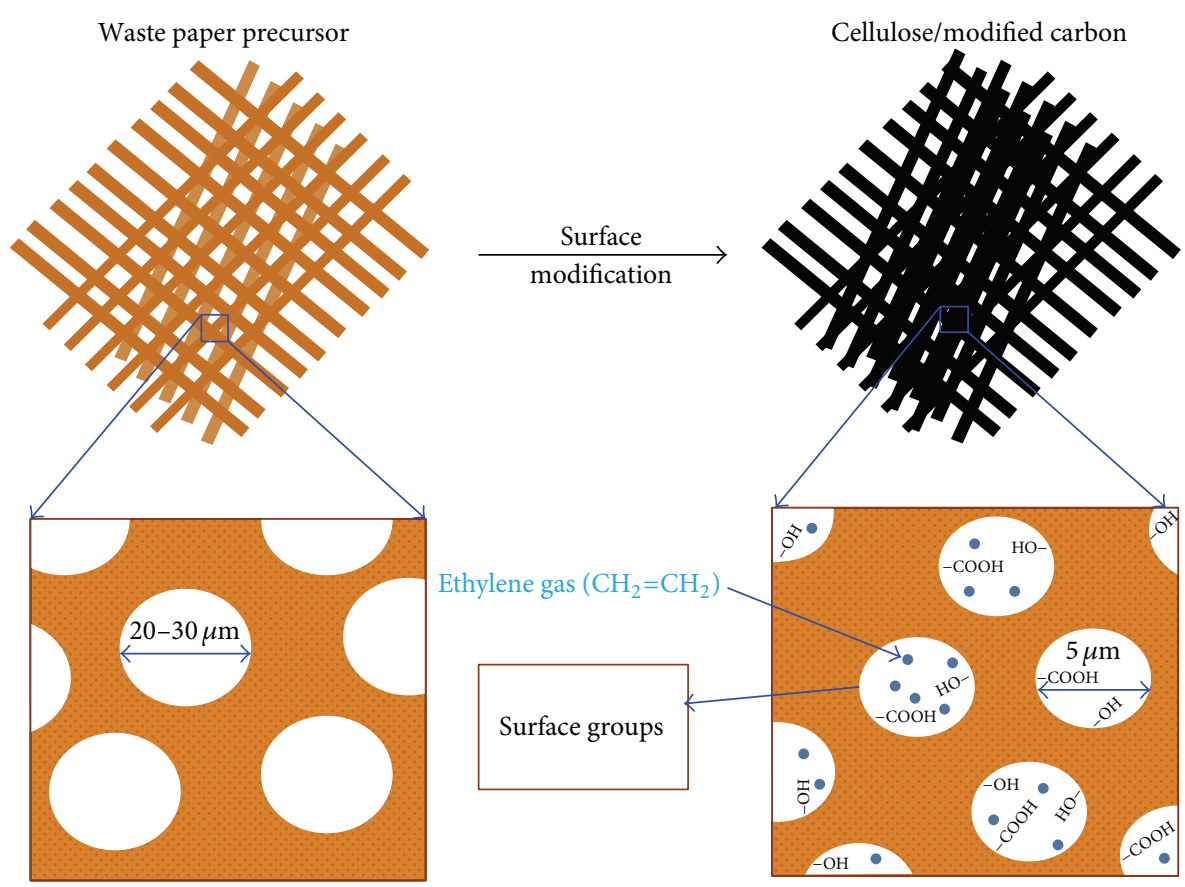

Figure 9: Mechanism of ethylene gas absorption on activated carbon and cellulose composite.

thus transmitted and it can be therefore stored on the surface of activated carbon. Three times oxygen permeation ability was therefore observed for waste composite compared to neat cellulose sheet.

Contrary to ethylene adsorption ability, the ability of ethylene gas absorption was therefore detrimental. Waste composite with $10 \mathrm{wt} \%$ reinforcement of activated carbon was provided the superiority on technical data. The investigation was conducted for 10 hours. The reason was due to the fact that, with excess integration of activated carbon, it may adsorb water and air from environment. The less space for ethylene gas absorption was consequently provided. Another reason was due to agglomeration on activated carbon. It may provide significant reduction on ethylene adsorption ability.

Figure 9 exhibits the ethylene gas absorption mechanism of activated carbon and cellulose composite. It was important to note that, without activated carbon, chemical reactive groups such as $-\mathrm{OH}$ and $-\mathrm{COOH}$ do not exist. The role of modified activated carbon can be induced to have the chemical bonding between ethylene gas and reactive functional group within the porous structure of modified carbon inserted to cellulose matrix. The small size of porosity provided significant efforts on specific surface area, rendering the existence of modified activated carbon which can induce superiority in absorption compared to neat cellulose.

\section{Conclusion}

Activated carbon was successfully derived from scrap tile waste from thermochemical conversion. The high performance in specific surface area and porosity was therefore observed after chemical modification. Cellulose was successfully extracted from palm front. The morphological properties of derived cellulose acted as network-like structure. Designation of waste composite was prepared between cellulose and activated carbon. Young's modulus and tensile strength of composite were reduced, while elongation at break was increased. It was important to note that there is no change in morphological properties. The existence of activated carbon was in the pore of cellulose network. Oxygen permeation rate was reduced for waste composite, while ethylene gas adsorption was increased. Waste composite presented the strong idea on the utilization for being ethylene absorber for food packaging.

\section{Competing Interests}

There is no conflict of interests regarding the publication of this paper.

\section{Acknowledgments}

The authors gratefully acknowledge the financial support from NSTDA University Industry Research Collaboration (NUI-RC). The authors also acknowledge the Center for Advanced Studies in Materials and Packaging TU Institute for Advanced Studies, Faculty of Science and Technology, Thammasat University.

\section{References}

[1] S. Ummartyotin and M. Sain, "Preparation of a cellulose and water-based resin composite," Materials Letters, vol. 123, pp. 7074, 2014. 
[2] K. Rittirong, S. Uasopon, P. Prachayawasin, N. Euaphantasate, K. Aiempanakit, and S. Ummartyotin, "CTAB as a soft template for modified clay as filler in active packaging," Data in Brief, vol. 3, pp. 47-50, 2015.

[3] S. Ummartyotin and H. Manuspiya, "A critical review on cellulose: from fundamental to an approach on sensor technology," Renewable and Sustainable Energy Reviews, vol. 41, pp. 402-412, 2015.

[4] S. Ummartyotin and H. Manuspiya, "An overview of feasibilities and challenge of conductive cellulose for rechargeable lithium based battery," Renewable and Sustainable Energy Reviews, vol. 50, pp. 204-213, 2015.

[5] S. Ummartyotin and B. Tangnorawich, "Utilization of eggshell waste as raw material for synthesis of hydroxyapatite," Colloid and Polymer Science, vol. 293, no. 9, pp. 2477-2483, 2015.

[6] S. Ummartyotin and C. Pechyen, "Microcrystalline-cellulose and polypropylene based composite: a simple, selective and effective material for microwavable packaging," Carbohydrate Polymers, vol. 142, pp. 133-140, 2016.

[7] S. Ummartyotin, J. Juntaro, M. Sain, and H. Manuspiya, "Development of transparent bacterial cellulose nanocomposite film as substrate for flexible organic light emitting diode (OLED) display," Industrial Crops and Products, vol. 35, no. 1, pp. 92-97, 2012.

[8] P. Sathishkumar, M. Arulkumar, and T. Palvannan, "Utilization of agro-industrial waste Jatropha curcas pods as an activated carbon for the adsorption of reactive dye Remazol Brilliant Blue R (RBBR)," Journal of Cleaner Production, vol. 22, no. 1, pp. 6775, 2012.

[9] S. K. Najafi, "Use of recycled plastics in wood plastic composites-a review," Waste Management, vol. 33, no. 9, pp. 1898-1905, 2013.

[10] S. Kang, H. Li, J. Lei, L. Liu, B. Cai, and G. Zhang, "A new utilization approach of the waste heat with mid-low temperature in the combined heating and power system integrating heat pump," Applied Energy, vol. 160, pp. 185-193, 2015.

[11] X. Yang, H. S. Choi, C. Park, and S. W. Kim, "Current states and prospects of organic waste utilization for biorefineries," Renewable and Sustainable Energy Reviews, vol. 49, pp. 335-349, 2015.

[12] W. M. Budzianowski, "A review of potential innovations for production, conditioning and utilization of biogas with multiplecriteria assessment," Renewable and Sustainable Energy Reviews, vol. 54, pp. 1148-1171, 2016.

[13] K. O'Callaghan, "Technologies for the utilisation of biogenic waste in the bioeconomy," Food Chemistry, vol. 198, pp. 2-11, 2016.

[14] N. Chaukura, W. Gwenzi, T. Bunhu, D. T. Ruziwa, and I. Pumure, "Potential uses and value-added products derived from waste polystyrene in developing countries: a review," Resources, Conservation and Recycling, vol. 107, pp. 157-165, 2016.

[15] A. Jain, R. Balasubramanian, and M. P. Srinivasan, "Hydrothermal conversion of biomass waste to activated carbon with high porosity: a review," Chemical Engineering Journal, vol. 283, Article ID 14005, pp. 789-805, 2016.

[16] M. J. Ahmed and M. Ahmaruzzaman, "A review on potential usage of industrial waste materials for binding heavy metal ions from aqueous solutions," Journal of Water Process Engineering, vol. 10, pp. 39-47, 2016.
[17] B. Acevedo and C. Barriocanal, "Texture and surface chemistry of activated carbons obtained from tyre wastes," Fuel Processing Technology, vol. 134, article 4451, pp. 275-283, 2015.

[18] B. Acevedo, C. Barriocanal, I. Lupul, and G. Gryglewicz, "Properties and performance of mesoporous activated carbons from scrap tyres, bituminous wastes and coal," Fuel, vol. 151, pp. 83-90, 2015.

[19] R. Acosta, V. Fierro, A. Martinez de Yuso, D. Nabarlatz, and A. Celzard, "Tetracycline adsorption onto activated carbons produced by $\mathrm{KOH}$ activation of tyre pyrolysis char," Chemosphere, vol. 149, pp. 168-176, 2016.

[20] P. Hadi, K. Y. Yeung, J. Guo, H. Wang, and G. McKay, "Sustainable development of tyre char-based activated carbons with different textural properties for value-added applications," Journal of Environmental Management, vol. 170, pp. 1-7, 2016.

[21] N. A. S. Ramli and N. A. S. Amin, "Catalytic hydrolysis of cellulose and oil palm biomass in ionic liquid to reducing sugar for levulinic acid production," Fuel Processing Technology, vol. 128, pp. 490-498, 2014.

[22] W. R. W. Daud and F. M. Djuned, "Cellulose acetate from oil palm empty fruit bunch via a one step heterogeneous acetylation," Carbohydrate Polymers, vol. 132, article 9995, pp. 252-260, 2015.

[23] J. Lamaming, R. Hashim, O. Sulaiman, C. P. Leh, T. Sugimoto, and N. A. Nordin, "Cellulose nanocrystals isolated from oil palm trunk," Carbohydrate Polymers, vol. 127, pp. 202-208, 2015.

[24] M. L. Gerardo, S. Van Den Hende, H. Vervaeren, T. Coward, and S. C. Skill, "Harvesting of microalgae within a biorefinery approach: a review of the developments and case studies from pilot-plants," Algal Research, vol. 11, pp. 248-262, 2015.

[25] T. Suganya, M. Varman, H. H. Masjuki, and S. Renganathan, "Macroalgae and microalgae as a potential source for commercial applications along with biofuels production: a biorefinery approach," Renewable and Sustainable Energy Reviews, vol. 55, pp. 909-941, 2016. 

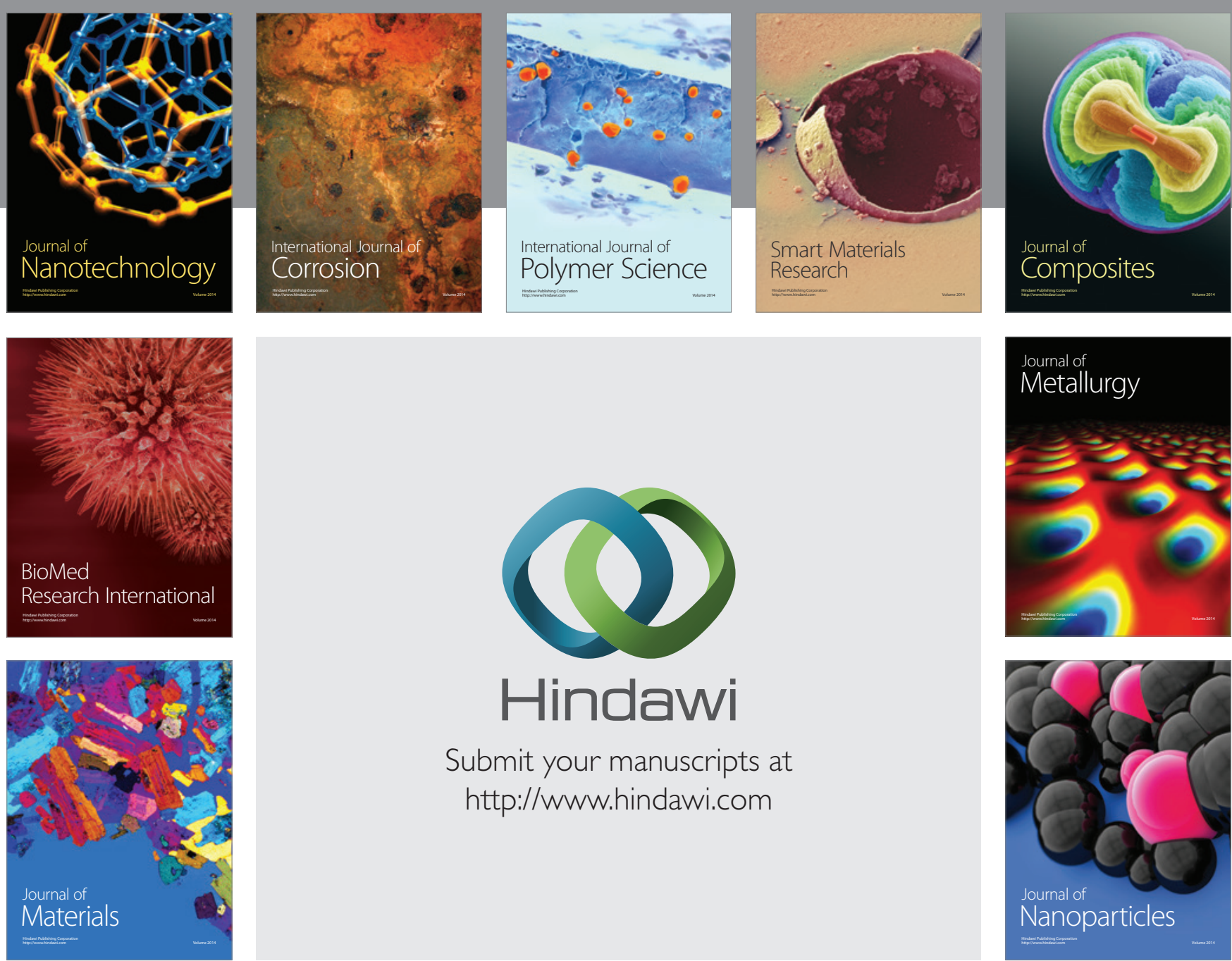

\section{Hindawi}

Submit your manuscripts at

http://www.hindawi.com

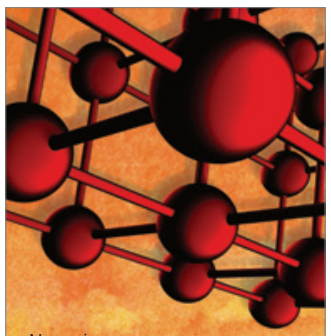

Materials Science and Engineering
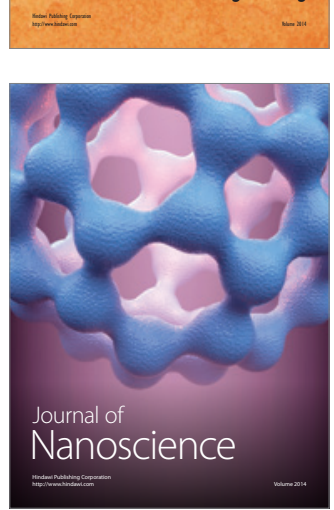
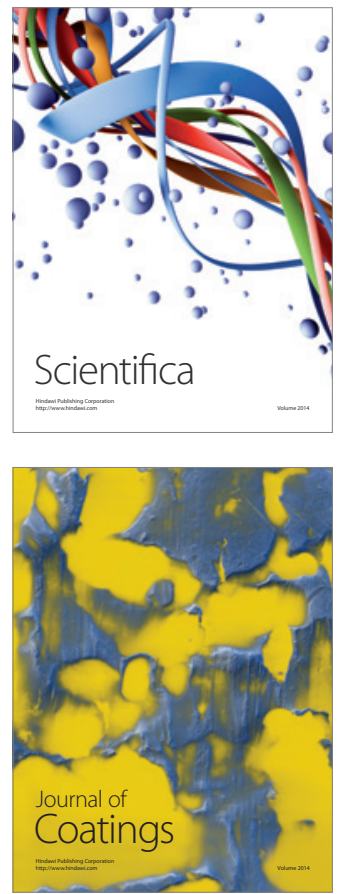
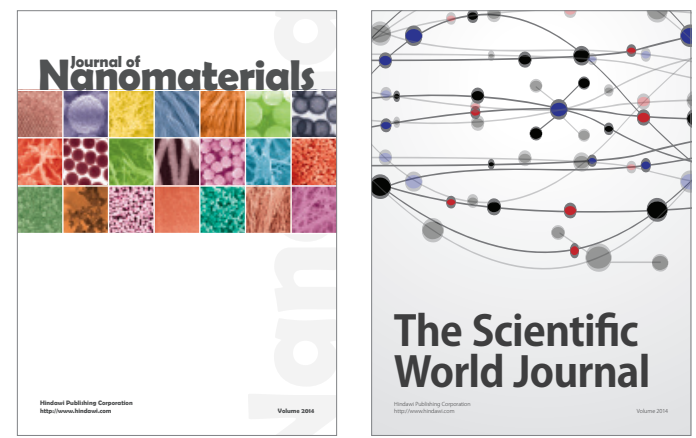

The Scientific World Journal
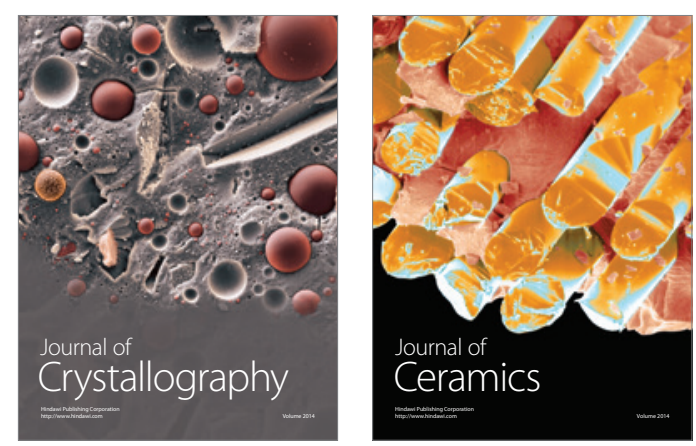
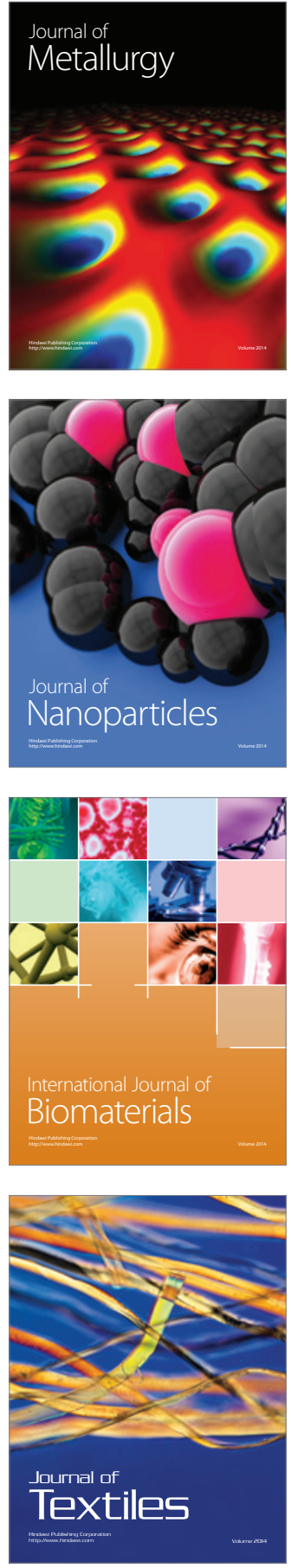